\title{
Development Approaches of Teachers Supporting Education Under the New Situations Yunfan Chen ${ }^{1, a}$
}

\author{
${ }^{1}$ Chengdu Jiaxiang Foreign Languages School, Chengdu, 610412, China \\ ${ }^{\mathrm{a}}$ email
}

Keywords: Support education, Rural education, Poverty alleviation

\begin{abstract}
Through the questionnaire survey form, the paper investigated the two hundred teachers supporting rural education in Jiangyou County in Sichuan Province from the perspectives of age structure, degree distribution, work time, turnover reasons, reasons for supporting rural education to analyze the overall individual situation of teachers supporting education as well as some changes in the teaching process. Finally, measures to solve such problems from the government and social levels are put forward in the paper.
\end{abstract}

\section{Introduction}

At present, in face of the fierce competition in the global market, China has achieved tremendous economic achievements. The overall national strength has been rising and the international status has been improved. China plays an important role in the international economic competition. However, China's domestic economic development is uneven, as reflected in the rapid development of urban economy and the higher level of urban education. China's rural education is confronted with the problems of lack of capital, shortage of teachers, poor quality of teachers and unequal allocation of teachers. The situation of the huge economic gap between the urban and rural areas in China and the unequal education development triggers our thinking of the education.

Through the questionnaire survey form, the paper investigated the two hundred teachers supporting rural education in Jiangyou County in Sichuan Province from the perspectives of age structure, degree distribution, work time, turnover reasons, reasons for supporting rural education to analyze the overall individual situation of teachers supporting education as well as some changes in the teaching process. Finally, measures to solve such problems from the government and social levels are put forward in the paper.

Unequal distribution of teachers will lead to unequal education. In order to avoid the serious influence of the unequal distribution of teachers, we should try to balance the teacher quality at different levels. It will help to improve the knowledge level of different students. In general, good teachers will work in the well-developed schools with abundant facilities. This will help them achieve their career planning and also enable the students obtain more educational resources. Therefore, the development of supporting education work in the central and western regions needs the high-quality teachers team. At the same time, it is necessary to provide good facilities resources for the teachers.

\section{Research Design and Process}

Research Questions. The research questions of the investigation are as follows:

1. What is the age structure distribution of the teachers supporting rural education? Which age group of teachers accounts for the majority? We should analyze the reasons for the age distribution difference.

2. What is the degree distribution of the teachers supporting rural education? We should analyze the reasons for the difference of the degree distribution.

3. How about the time distribution of the teachers supporting rural education?

4. What are the reasons for the turnover of the teachers supporting rural education. We should seek and analyze the problems revealed in the turnover reasons. 
5. What are the reasons for the teachers to support the rural education? How should the government guide the education support?

Research Methods. The survey was conducted among the two hundred teachers supporting education in Jiangyou county of Sichuan province. The questionnaire mainly studies the individual situation of the teachers who support the rural education, including the differences change based on the statistical quantities. In the study of their turnover situation, we explored the long-term existing problems in the education support process in depth. At the same time, we explored the major countermeasures which can help improve the enthusiasm of teachers to support education and promote long-term support.

Analysis and Result Discussion. Age distribution of teachers supporting education: There are 30 teachers whose age range from 18 to 21, accounting for $15.0 \%$; there are 110 teachers whose age range from 22 to 25 , accounting for $15.0 \%$; there are 52 teachers whose age range from 26 to 30 , accounting for $26.0 \%$; there are 8 teachers whose age are older than 31 , accounting for $4.0 \%$. We can easily discover that the teachers whose age range from 22 to 25 accounting for more than half of the investigated teachers. People at the age of 22 to 25 are the younger generation teachers.

Degree distribution of teachers supporting education: There are 94 teachers whose degree are technical secondary school (including vocational school), accounting for $47.0 \%$; there are 68 teachers who have college degrees, accounting for $34.0 \%$; there are 35 teachers who have university degrees, accounting for $17.5 \%$; there are 3 teachers who have master degrees, accounting for $1.5 \%$. We can discover that the people who have the degree of technical secondary school (including vocational school) or college degree are the dominant teachers supporting education. However, the number of teachers who have the university degree or master degree are relatively low. It reflects the different perceptions of education support of different intellectual groups.

Work time distribution of teachers supporting education: There are 35 teachers whose work time are lower than one year, accounting for $27.5 \%$; there are 85 teachers whose work time ranges from one year to three years, accounting for $42.5 \%$; there are 46 teachers whose work time ranges from four years to six years, accounting for $23.0 \%$; there are 14 teachers whose work time is more than seven years, accounting for $7.0 \%$. The teachers who support the rural education for one year to three years account for the largest proportion. The teachers who support the rural education for more than seven years account for the smallest promotion.

Turnover reasons distribution of teachers supporting education: There are 35 teachers who leave the education support job for the reason of job changes, accounting for $31.0 \%$; there are 88 teachers who leave the education support job for the reason of further education, accounting for $44.0 \%$; there are 8 teachers who leave the education support job for the body reasons, accounting for $4.0 \%$; there are 42 teachers who leave the education support job for other reasons, accounting for $21.0 \%$. Among them, the teachers willing to conduct further education are the dominant teachers supporting education, which reflects the changes of psychological level of the teachers supporting education. At the same time, the physical reason is also listed in the influence factors, which reflects the physical qualities of the teachers supporting education as well as the backward realistic conditions in the rural areas.

Participation reasons distribution of teachers supporting education: There are 69 teachers who participate in the education support for the reasons of deep love for the educational, accounting for $34.5 \%$; there are 62 teachers who participate in the education support for the reasons of caring hearts, accounting for $31.0 \%$; there are 52 teachers who participate in the education support for the reasons of bearing social responsibilities, accounting for $26.0 \%$; there are 17 teachers who participate in the education support for other reasons, accounting for $8.5 \%$. It is not difficult to find that the proportion of people who love education deeply is the largest, which shows the influence of career planning on the significance of education support. At the same time, caring hearts and social responsibilities are immediately behind, indicating the impact of social moralities and responsibilities on teachers supporting education. 
Research on Turnover Problems. We establish the multiple regression model to study causes of turnover of the teachers supporting education by Matlab2016a and explore the hidden information to provide a solid foundation to conduct the education support in the rural areas in the future.

Due to the great differences among the data, we adopt the normalization process of the data to avoid the so-called phenomenon of "big number eat small number" to avoid errors.

The formulation of the normalization process is as follows:

$$
x_{i}^{*}=\frac{x_{i}-x_{\min }}{x_{\max }-x_{\min }} .
$$

There are two forms of the normalization. One is to change the number into the decimal between 0 and 1 . The other is to change the dimensional expression to the dimensionless expression. It is proposed for the convenient processing of the data. We map the data into the decimal between 0 and 1for more convenient processing, which should be incorporated into the scope of digital signal processing.

In the above formulation, $\mathrm{x}_{\mathrm{i}}$ and $\mathrm{x}_{\mathrm{i}}{ }^{*}$ respectively represent the values before and after the process of the normalization. $\mathrm{x}_{\min }$ and $\mathrm{x}_{\max }$ respectively represent the minimum value and the maximum value in the sample data.

Assume $\mathrm{y}$ is the dependent variable, and $\mathrm{x}_{1}, \mathrm{x}_{2}, \ldots$, and $\mathrm{x}_{\mathrm{n}}$ are the independent variables, when the relationship between the dependent variable and the independent variables is linear relationship, the model of the multiple linear regression is:

$$
y=b_{0}+b_{1} x_{1}+b_{2} x_{2}+\cdots+b_{k} x_{k}+e
$$

In the above formulation, $b_{0}$ is the constant term and the $b_{1}, b_{2}, \ldots$, and $b_{n}$ are the regression coefficients. Assume $b_{1}$ is fixed, the effectiveness of $y$ when $x_{1}$ increases one additional unit is the partial regression coefficient of $\mathrm{x}_{1}$ to $\mathrm{y}$. Similarly, assume $\mathrm{b}_{2}$ is fixed, the effectiveness of $\mathrm{y}$ when $\mathrm{x}_{2}$ increases one additional unit is the partial regression coefficient of $\mathrm{x}_{2}$ to $\mathrm{y}$. If the two independent variables of $\mathrm{x}_{1}$ and $\mathrm{x}_{2}$ are linearly related with one dependent variable $\mathrm{y}$, we can adopt the model of the binary linear regression to describe the relationship:

$$
y=b_{0}+b_{1} x_{1}+b_{2} x_{2}+\cdots+b_{k} x_{k}+e
$$

In the above formulation, $b_{0}$ is the constant term and the $b_{1}, b_{2}, \ldots$, and $b_{k}$ are the regression coefficients. Assume $b_{1}$ is fixed, the effectiveness of $y$ when $x_{2}$ increases one additional unit is the partial regression coefficient of $\mathrm{x}_{2}$ to $\mathrm{y}$.

Among the data, we adopt the working status as the dependent variable $\mathrm{y}$. The independent variables $\mathrm{x}_{1}, \mathrm{x}_{2}, \mathrm{x}_{3}, \mathrm{x}_{4}$ and $\mathrm{x}_{5}$ respectively represent the work time (days), physical condition (outstanding $=2$, good $=1$ and bad=0), work wages, education degrees and individual marriage (yes=0, no=1).

Multiple linear regression model is used to establish the model, find the relationship among the dependent status of working status $\mathrm{y}$ and the independent variables $\mathrm{x}_{1}, \mathrm{x}_{2}, \mathrm{x}_{3}, \mathrm{x}_{4}$ and $\mathrm{x}_{5}$ to adjust the arrangement of education support and promote the enthusiasm of teachers supporting education and the rationality of their work.

We get multiple regression analysis of the sample data by Matlab. The results are shown in Table 1. 
Table 1. Results including the uneliminated outliers

\begin{tabular}{|c|c|c|}
\hline Regression coefficient & $\begin{array}{c}\text { Estimated value of } \\
\text { regression coefficient }\end{array}$ & $\begin{array}{c}\text { Confidence interval regression } \\
\text { coefficient }\end{array}$ \\
\hline$\beta 0$ & 3.3636 & {$[3.5537,4.7698]$} \\
\hline$\beta 1$ & 0.5604 & {$[-0.0758,0.7965]$} \\
\hline$\beta 2$ & 1.2654 & {$[0.5489,3.2569]$} \\
\hline$\beta 3$ & 2.9645 & {$[1.2457,4.0256]$} \\
\hline$\beta 4$ & 0.0925 & {$[0.0001,0.2352]$} \\
\hline$\beta 5$ & 0.1125 & {$[0.0532,0.4325]$} \\
\hline \multicolumn{2}{|r}{} & $\mathrm{R}^{2}=0.9331 \mathrm{~F}=18.8906 \mathrm{P}<0.001 \mathrm{~S}^{2}=169.7971$ \\
\hline
\end{tabular}

The regression model can be obtained. The result is shown as follows:

$$
\hat{y}=3.3636+0.5604 x_{1}+1.2654 x_{2}+2.9645 x_{3}+0.0925 x_{4}+0.1125 x_{5}
$$

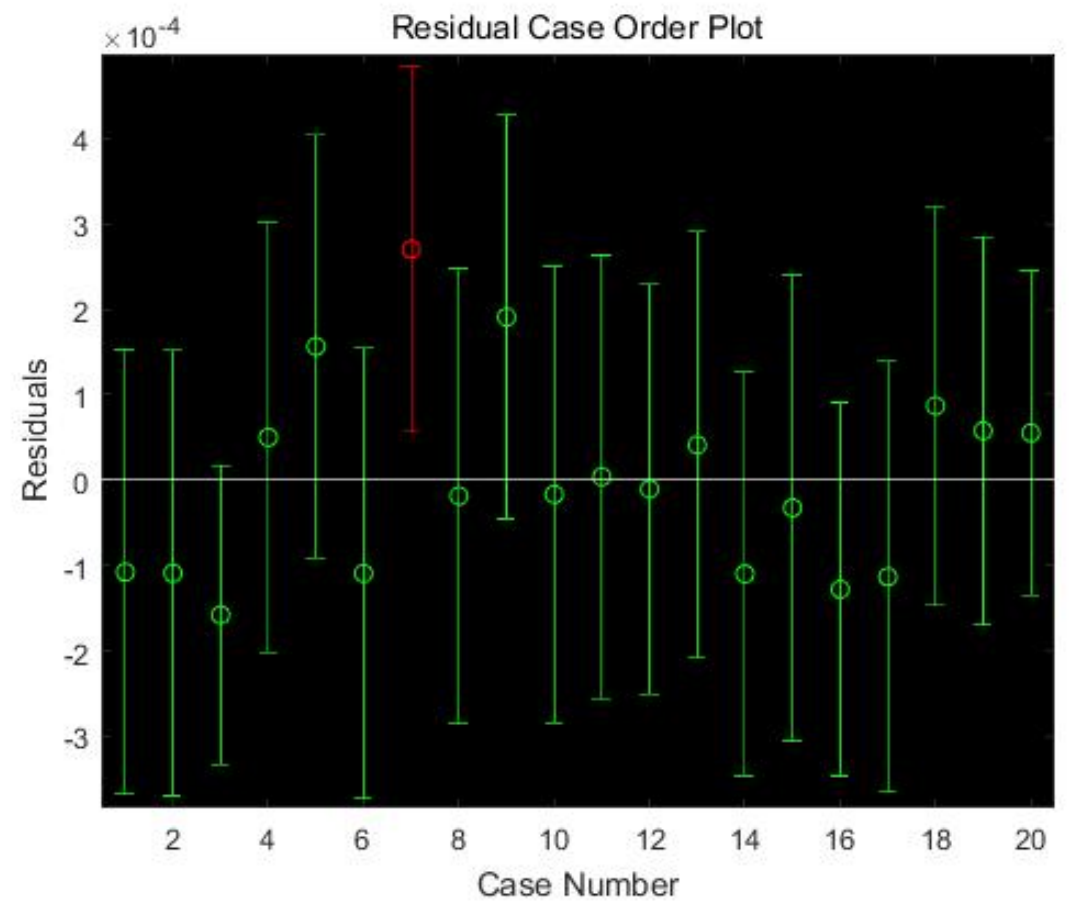

Figure 1. Residual case order plot

The outliers are shown in Figure 1. We eliminate the outliers to establish a new regression model. The results are shown in Table 2 .

Table 2. Results after eliminating the outliers

\begin{tabular}{|c|c|c|}
\hline Regression coefficient & $\begin{array}{l}\text { Estimated value of } \\
\text { regression coefficient }\end{array}$ & Confidence interval regression coefficient \\
\hline$\beta 0$ & 4.7126 & {$[3.5537,5.9826]$} \\
\hline$\beta 1$ & 0.5922 & {$[-0.0653,0.9075]$} \\
\hline$\beta 2$ & 1.1634 & {$[0.6473,3.8739]$} \\
\hline$\beta 3$ & 2.6325 & {$[1.2457,5.3756]$} \\
\hline$\beta 4$ & 0.1225 & {$[0.0011,0.3332]$} \\
\hline$\beta 5$ & 0.0935 & {$[0.0356,0.3958]$} \\
\hline \multicolumn{3}{|c|}{$\mathrm{R} 2=0.9422 \mathrm{~F}=18.8952 \mathrm{P}<0.001 \mathrm{~S} 2=109.7052$} \\
\hline
\end{tabular}




$$
\hat{y}=4.7126+0.5922 x_{1}+1.1634 x_{2}+2.6325 x_{3}+0.1225 x_{4}+0.0935 x_{5}
$$

Through the multiple linear regression model, we can see that the factors which are closely related to the teaching work of the teachers support education are physical conditions, work wages as well as work time. Therefore, the department concerned should develop appropriate strategies to satisfy the teachers demand of the rural areas. At the same time, the department concerned should pay attention to the health level and living standard quality of the teachers who support the rural education.

\section{Conclusions}

Through the questionnaire survey form, the paper investigated the two hundred teachers supporting rural education in Jiangyou County in Sichuan Province from the perspectives of age structure, degree distribution, work time, turnover reasons, reasons for supporting rural education to analyze the overall individual situation of teachers supporting education as well as some changes in the teaching process. On the whole, in order to meet the needs of teachers supporting education in the rural areas, the social education support organizations should maintain effective communication with the local governments and schools. In the process of education support, the understanding and cooperation of local schools and governments is an important guarantee for the education support activities.

No matter what form of the education support and what kind the education policy, only when the local government and supported schools cooperate, the education support can play the biggest role. Schools and local governments should do their best to support the students who will participate in the education support activities to provide help within their ability. In addition, teachers can carry out social research and organize small volunteer projects to investigate the actual needs of local schools and communities. Realize the education support demand truly. Attract the excellent teachers stay in the rural areas to support education for a long time. At the same time, the development of education support by the university students is an important method to solve the problems.

\section{References}

[1] Huang Xu. Investigation on the Subject of Supporting Rural Education by Chengdu Teachers [J]. Education and Teaching Research, 2011, 25(4): 22-25.

[2] Li Jianqiang, Liu Sen, Li Qingda. Teaching Practice Supporting Education: Realistic Choice of Promising Role in Normal Universities-Experience from Hebei Normal University [J]. Teacher Education Research, 2007, 19(6): 67-71.

[3] Yang Guiping. Poverty Alleviation through Supporting Rural Education for 30 Years: Zigen Experience [J]. China Agricultural University Journal of Social Sciences Edition, 2016, 33(5): 109-118.

[4] Dai Xiaoming. Education: The Core of Targeted Poverty Alleviation in Ethnic Regions-Investigation and Reflection of a Remote Village Primary School in Wuling Mountain Area [J]. Journal of Minzu University of China (Philosophy and Social Sciences Edition), 2016, 43(6): 70-74. 